\title{
BMJ Open Cost analysis of staged versus simultaneous bilateral total knee and hip arthroplasty using a propensity score matching
}

\author{
Ji-Fei Hou, ${ }^{1,2}$ Chuan Hu, ${ }^{1,2}$ Yun Zhang (D) , ${ }^{1}$ Li-Qi Tian, ${ }^{1}$ Yan-Zheng Liu, ${ }^{3}$ \\ Chi Zhang, ${ }^{1,2}$ Jing $\mathrm{Li}^{1}$
}

To cite: Hou J-F, Hu C, Zhang Y, et al. Cost analysis of staged versus simultaneous bilateral total knee and hip arthroplasty using a propensity score matching. BMJ Open 2021;11:e041147. doi:10.1136/ bmjopen-2020-041147

- Prepublication history for this paper is available online. To view these files, please visit the journal online (http://dx.doi. org/10.1136/bmjopen-2020041147).

$\mathrm{J}-\mathrm{FH}$ and $\mathrm{CH}$ contributed equally. $\mathrm{YZ}$ and $\mathrm{L}-\mathrm{QT}$ contributed equally.

Received 02 June 2020 Revised 28 December 2020 Accepted 05 January 2021

Check for updates

(c) Author(s) (or their employer(s)) 2021. Re-use permitted under CC BY-NC. No commercial re-use. See rights and permissions. Published by BMJ.

${ }^{1}$ The Affiliated Hospital of Qingdao University, QingDao, China

${ }^{2}$ Medical College, Qingdao University, Qingdao, China ${ }^{3}$ Department of Research, Qilu Hospital,Cheeloo College of Medicine,Shandong University, Jinan, China

Correspondence to

Yun Zhang;

18186532881@163.com

\section{ABSTRACT}

Background Total joint arthroplasty (TJA), including total knee arthroplasty (TKA) and total hip arthroplasty (THA), is required for many patients. This study aimed to evaluate the medical costs, length of stay (LOS), blood transfusion and in-hospital complications in patients undergoing simultaneous and staged TJA.

Methods All patients who underwent primary bilateral TJA from 2013 to 2018 in our institute were included. The propensity score matching analysis was performed between simultaneous and staged TJA patients. The difference in medical costs, LOS, blood transfusion and in-hospital complications was compared between simultaneous and staged groups.

Results Except for materials fees and general therapy fees, medical costs (bed fees, general therapy fees, nursing care fees, check-up and laboratory test fees, surgical fees and drug fees) were significantly lower in the simultaneous TKA, THA and TJA group. The total average medical costs in simultaneous and staged TKA groups were $\$ 15385$ and $\$ 16729(p<0.001)$, respectively; THA groups were $\$ 14503$ and $\$ 16142(p=0.016)$, respectively; TJA groups were $\$ 15389$ and $\$ 16830$ $(p<0.001)$, respectively. The highest and lowest costs were materials fees and nursing care fees. No significant differences were found for five common comorbidities and postoperative complications between the two subgroups. The simultaneous groups had a shorter LOS and the differences from the staged group for TKA, THA and the TJA group were 8,6 and 8 days, respectively. The incidence of blood transfusion is higher for simultaneous groups and the difference from the staged group for TKA THA and TJA is $32.69 \%, 18 \%$ and $29.3 \%$, respectively.

Conclusions Our results indicate that simultaneous TKA and THA with a shorter LOS would cost fewer (costs incurred during hospitalisation) than staged TKA and THA. Complication rates were not affected by the choice for staged or simultaneous arthroplasty, but the incidence of blood transfusion was higher in the simultaneous groups.

\section{INTRODUCTION}

Total joint arthroplasty (TJA), including total knee arthroplasty (TKA) and total hip arthroplasty (THA), is a cost-effective procedure for patients with advanced arthropathies,
Strengths and limitations of this study

We did not analyse too many clinical outcomes because of the limitation of data.

- As a retrospective study, it lacks readmission and discharge disposition data.

- The cost comparison is limited to the medical expenses incurred during the patient's hospitalisation.

- A direct comparison of actual hospital costs combined with some clinical outcomes.

- We used propensity matching to compare total knee arthroplasty, total hip arthroplasty and total joint arthroplasty patients in the same cohort.

such as osteoarthritis (OA), which can significantly improve the quality of life for these patients. ${ }^{1-3}$ With the population ages, the number of arthropathies is projected to continue growing in many countries. ${ }^{2}{ }^{2-6}$ A recent study from the USA predicted the volume of TJA and concluded that THA is projected to grow $71 \%$, to 635000 procedures, and TKA is projected to grow $85 \%$, to 1.26 million procedures, by $2030{ }^{4}$

Besides, the increased arthroplasty procedures will result in a huge economic burden for both the families and the public healthcare system. ${ }^{2}$ 7-10 As China's healthcare expenditures are soaring, ${ }^{11}$ the government has sought to reduce the overall cost of arthroplasty procedures by shortening average length of stay (LOS), strengthening the supervision of surgical procedures and optimising the management of purchasing medical disposable materials.

Usually, bilateral TJA can be performed simultaneously under the same anaesthetic during one hospitalisation, or performed as staged bilateral procedures, with two unilateral arthroplasties under separate anaesthetics and hospitalisations. These are two different strategies for surgical procedures. 
However, there exists debate regarding staged or simultaneous bilateral TJA, and the major controversy is the outcome of two procedures. ${ }^{7}$ The comparison between the two types of surgery is not consistent. Therefore, the surgeons and patients need some new evidence to decide whether to perform simultaneous bilateral or staged TJA for patients.

Previous studies about simultaneous bilateral or staged TJA have made some progress. But their research focuses always concentrated on clinical outcomes, such as operative and anaesthetic times, EuroQol-5D index, healthrelated quality of life, blood loss, Harris hip score and in-hospital mortality rates. ${ }^{12-14}$ Relative to staged TKA, simultaneous TKA is associated with higher 10-year prosthesis survival rates, ${ }^{2}$ longer quality-adjusted life years ${ }^{15}$ more economical time for physiotherapists, fewer anaesthetics and hospitalisations ${ }^{16}$ and lower frequency of knee infection $^{12}$; no significant difference in Knee Society Score, Western Ontario and McMaster Universities Arthritis Index and range of motion ${ }^{13}$; and higher in-hospital mortality, higher frequency of blood transfusions, higher frequency of transfer to a rehabilitation facility and higher rate of cardiac complications within 90 days. ${ }^{12}$

Compared with staged bilateral procedures of THA, simultaneous THA has been associated with shorter operative and anaesthetic times, less blood $\operatorname{loss}^{1}$ and similar improvements in patient-reported outcomes at 1-year follow-up. Most clinical outcomes were better for simultaneous TKA and THA. Whereas to the best of our knowledge, no recent study has presented a direct comparison of actual hospital costs for both TKA and THA in the same cohort study; for any decisions are not usually based solely on costs or clinical outcomes, but a combination of them. Yet there is no consensus on which procedure (simultaneous vs staged bilateral TKA or THA) is better.

Several retrospective cohort studies on the topic did not adjust for confounders that were associated with treatment selection and that also predisposed a patient to a poor outcome (eg, increased age or comorbidity). In our research, we sought to provide data on this issue among equivalent patients in a large, population-based, propensity score-matched cohort. This study aimed to investigate differences in cost, in-hospital complications, blood transfusion and LOS in three groups (TKA, THA and TJA), respectively. Besides, subgroup analyses of cost, in-hospital complications, blood transfusion and LOS were performed in staged and simultaneous bilateral TJA groups.

\section{METHODS}

\section{Study design and data sources}

After the Ethics Committee of the Affiliated Hospital of Qingdao University was approved, we obtained the data of patients who underwent primary TKA or THA from January 2013 to December 2018 in the Affiliated Hospital of Qingdao University, a 5046-bed urban, third-grade class A, the medical school-affiliated hospital in Qingdao,
Shandong (third grand class A is the highest level in the hospital classification in China).

Anonymous clinical data were extracted from the hospital information system of our hospital, including baseline information of the patient, in-hospital costs, LOS, indications of operation by International Classification of Diseases, 10th revision, in-hospital complications (complications include haematoma, surgical site infection, periprosthetic joint infection, periprosthetic femoral fracture, dislocation, aseptic loosening, shock, myocardial infarction, heart failure, pulmonary embolism, cerebral infarction, delirium, acute stress ulcer, arrhythmia, acute renal injury, deep vein thrombosis, pneumonia, atelectasis, urinary tract infection and urinary retention), blood transfusion and detailed healthcare expenditure information. The duration of our analysis is from patient admission to discharge. For staged bilateral, they would include both admissions and discharges.

\section{Sample of patient selection}

The main diagnosis of our patients is OA. A patient who underwent two procedures separated within 1 year and by the same surgeon was considered to have undergone staged bilateral TKA or THA. Patients were included in the analysis if all cost, in-hospital complication, LOS and demographic data were available. Only seven patients were excluded due to incomplete data. We excluded patients who underwent revision arthroplasty and patients who underwent TJA of both sides during one hospitalisation, for these patients have undergone two unilateral surgeries but during one hospitalisation, and they were not simultaneous surgical patients who have only one surgery. We excluded those patients because they only need one medical examination, such as a lab test and imaging test, with a high rate of blood transfusion compared with staged patients who underwent two hospitalisations. We also excluded patients who have infectious joint disease, as those patients would cost more, and patients with fractures who have a very different clinical pathway. Patients were divided into three groups-THA, TKA and all patients, and then divided into two subgroups according to whether they were undergoing simultaneous bilateral TJA or staged bilateral TJA.

\section{Primary outcome: direct medical costs during hospitalisation}

Total medical expenses include bed fees, fees of general therapy, nursing care fees, check-up and laboratory test fees, surgical fees, drug fees and materials fees. Detailed introduction about all kinds of costs is shown in table 1 . Total hospital costs of the staged group used pooled data of the two procedures. To offset the influence of inflation and economic growth and to reflect the real dollar value, all expenditure variables in the present study were adjusted to Chinese currency values (2018) using the Consumer Price Index, ${ }^{17}$ and then all values were converted to US dollars (US\$) with the exchange rate ${ }^{18}$ of US $\$ 1=¥ 6.43$ (the averaged exchange rate throughout the study period from 2013 to 2018). 
Table 1 The introduction of all kinds of medical costs for patients

\begin{tabular}{|c|c|}
\hline Items & Description \\
\hline $\begin{array}{l}\text { Total medical } \\
\text { expenses }\end{array}$ & $\begin{array}{l}\text { The sum of health expenditures during } \\
\text { hospitalisation }\end{array}$ \\
\hline Bed fees & $\begin{array}{l}\text { Relatively fixed expenses for the bed } \\
\text { used by patients }\end{array}$ \\
\hline $\begin{array}{l}\text { Fees of general } \\
\text { therapy }\end{array}$ & $\begin{array}{l}\text { Including dressing change, injection, } \\
\text { catheterisation, oxygen absorption and } \\
\text { other costs }\end{array}$ \\
\hline Nursing care fees & $\begin{array}{l}\text { Relatively fixed cost of caring for } \\
\text { patients every day }\end{array}$ \\
\hline $\begin{array}{l}\text { Check-up and } \\
\text { laboratory test } \\
\text { fees }\end{array}$ & $\begin{array}{l}\text { Various medical equipment inspection } \\
\text { costs }\end{array}$ \\
\hline Surgical fees & $\begin{array}{l}\text { The cost of the surgical operation alone, } \\
\text { not including other expenses incurred } \\
\text { during the hospitalisation }\end{array}$ \\
\hline Drug fees & $\begin{array}{l}\text { Refer in particular to drugs used by } \\
\text { patients }\end{array}$ \\
\hline Materials fees & $\begin{array}{l}\text { A combination of various hygienic } \\
\text { consumables cost }\end{array}$ \\
\hline
\end{tabular}

\section{Secondary outcomes: in-hospital complications, blood transfusion and LOS}

One of the secondary outcomes of interest is in-hospital complications (including acute myocardial infarction, deep venous thrombosis, pulmonary embolism, ileus, renal failure, pneumonia and orthopaedic-specific complications). Other secondary outcomes of interest included perioperative transfusion rate and LOS. As for the staged surgery group, a total length of days of both surgeries was used as final LOS.

\section{Statistical analysis}

A propensity score for a patient undergoing a TKA, THA and TJA was performed separately, ${ }^{19}$ using callipers of a width equal to 0.2 of the SD of the logit of the propensity score via the greedy (or nearest neighbour without replacement) matching method. The covariates that were entered into the propensity score were social demographic (age, gender, body mass index/BMI) and health status (hypertension, diabetes, coronary heart disease, disease of the respiratory system, history of cerebral infarction). A matching ratio of 1:1 was used. We estimated the standardised differences for all covariates before and after matching, with a standardised difference of $\geq 10 \%$ considered indicative of imbalance. Hospitalisation expenses and clinical indicators were compared between the groups after matching.

The normality of continuous variables was assessed using the Kolmogorov-Smirnov test or Shapiro-Wilk test. Non-normally distributed variables were presented as medians and IQRs (the range between the 25th and 75th percentile), and categorical variables were presented by counts and percentages. Demographic and clinical data of patients were compared between groups with the $\mathrm{X}^{2}$ test for categorical variables and the Mann-Whitney $\mathrm{U}$ test for continuous variables. A two-sided $\mathrm{p}<0.05$ was considered as statistical significance. All statistical analyses were performed using SPSS software V.25.0 (IBM Corporation).

\section{Patient and public involvement \\ Patients and or the public were not involved.}

\section{RESULTS}

\section{Baseline characteristics prior to matching}

Between 2013 and 2018, a total of 8760 patients underwent arthroplasty in our hospital, and 1579 patients were enrolled in this study. Nine hundred twenty-nine cases were simultaneous TJA patients, and 650 cases were staged TJA patients. TJA patients are aggregate of THA and TKA. A total of 1180 patients underwent TKA, of which 789 were simultaneous TKA patients and 391 were staged TKA patients. For THA patients, 140 were simultaneous THA patients and 259 were staged THA patients. The baseline characteristics before matching were shown in table 2.

Simultaneous TKA patients were younger (64 vs 68 years, $\mathrm{p}<0.001)$ compared with staged TKA patients. The patients of staged bilateral THA were older ( 58 vs 53 years, $\mathrm{p}<0.01)$ than those simultaneous THA patients. Similar to trends for TKA and THA, simultaneous TJA was performed more frequently in younger patients (63 vs 64 years, $\mathrm{p}<0.05)$. For TJA, there was a difference in gender distribution (693 women vs 399 women, $p<0.01$ ) between simultaneous TJA patients and staged TJA patients (table 2).

\section{Baseline characteristics after matching}

After matching, we have a total of 618 patients included in the study for TKA, 200 patients for THA and 1058 patients for TJA. There was no significant difference ( $>0.05$ ) between patients who underwent simultaneous arthroplasty and those who underwent staged arthroplasty in terms of social demographic (age, gender, BMI) and health status (hypertension, diabetes, coronary heart disease, disease of the respiratory system, history of cerebral infarction) (table 3).

\section{Clinical characteristics after matching}

A summary of the clinical data of the patients of the three groups is shown in table 4. Simultaneous TKA patients have a higher incidence of blood transfusion $(40.78 \%$ vs $8.09 \%, \mathrm{p}<0.000$ ), and with a shorter LOS (9 vs 17 days, $\mathrm{p}<0.000)$ compared with staged TKA patients. But no significant difference was found for complications $(2.27 \%$ vs $2.91 \%$, yes, $\mathrm{p}=0.612$ ).

Simultaneous THA patients had a higher incidence of blood transfusion $(13.00 \%$ vs $31.00 \%$, yes, $p=0.002)$, and with a shorter LOS ( 15 vs 9 days, $\mathrm{p}<0.000)$ than those simultaneous THA patients. Same results as TKA groups 
Table 2 Baseline characteristics of patients (prior to matching)

\begin{tabular}{|c|c|c|c|c|c|c|c|c|c|}
\hline Groups & TKA & & & THA & & & TJA & & \\
\hline Variables & $\begin{array}{l}\text { Simultaneous } \\
(n=789)\end{array}$ & $\begin{array}{l}\text { Staged } \\
(n=391)\end{array}$ & $P$ value & $\begin{array}{l}\text { Simultaneous } \\
(n=140)\end{array}$ & $\begin{array}{l}\text { Staged } \\
(n=259)\end{array}$ & $\begin{array}{l}P \\
\text { value }\end{array}$ & $\begin{array}{l}\text { Simultaneous } \\
(n=929)\end{array}$ & Staged $(n=650)$ & $P$ value \\
\hline $\begin{array}{l}\text { Age, median (IQR) } \\
\text { years }^{\star}\end{array}$ & $64(60-69)$ & $68(63-73)$ & $<0.00$ & $53(47-60)$ & $58(49-64)$ & 0.001 & $63(58-68)$ & $64(58-70)$ & 0.030 \\
\hline Gender (female)† & $651(82.51 \%)$ & 314 (80.31\%) & 0.356 & 42 (30.00\%) & 85 (32.82\%) & 0.564 & 693 (74.60\%) & 399 (61.38\%) & $<0.00$ \\
\hline $\begin{array}{l}\text { BMl, median (IQR) kg/ } \\
\mathrm{m}^{2 \star}\end{array}$ & $\begin{array}{l}27.34(24.92- \\
30.08)\end{array}$ & $\begin{array}{l}27.64(25.39- \\
30.04)\end{array}$ & 0.149 & $\begin{array}{l}24.55(21.88- \\
26.98)\end{array}$ & $\begin{array}{l}24.57(22.58- \\
27.55)\end{array}$ & 0.279 & $\begin{array}{l}26.99(24.23- \\
29.66)\end{array}$ & $\begin{array}{l}26.73(24.03- \\
29.30)\end{array}$ & 0.119 \\
\hline Diabetes (yes)† & 124 (15.70\%) & $71(18.16 \%)$ & 0.228 & $7(5.00 \%)$ & $9(3.47 \%)$ & 0.459 & 131 (14.105\%) & $80(12.31 \%)$ & 0.303 \\
\hline $\begin{array}{l}\text { Coronary heart disease } \\
\text { (yes) } \dagger\end{array}$ & 126 (15.97\%) & 64 (16.37\%) & 0.861 & $1(0.71 \%)$ & $4(1.54 \%)$ & 0.477 & 127 (13.67\%) & 68 (10.46\%) & 0.057 \\
\hline $\begin{array}{l}\text { Disease of respiratory } \\
\text { system (yes) } \dagger\end{array}$ & 35 (4.44\%) & $23(5.88 \%)$ & 0.280 & $3(2.14 \%)$ & $8(3.09 \%)$ & 0.582 & 38 (4.09\%) & 31 (4.77\%) & 0.516 \\
\hline
\end{tabular}

${ }^{*}$ Continuous data were presented as median (IQR) and compared by Mann-Whitney $U$ test.

†Categorical variables were expressed by counts and percentages and compared by the $\mathrm{X}^{2}$ test or the Fisher's exact test, as appropriate.

BMI, body mass index; THA, total hip arthroplasty; TJA, total joint arthroplasty; TKA, total knee arthroplasty.

for the count of complications $(2.00 \%$ vs $4.00 \%$, yes, $\mathrm{p}=0.407$ ).

For TJA, simultaneous groups with a higher incidence of blood transfusion $(40.30 \%$ vs $11.00 \%$, yes, $\mathrm{p}<0.000)$ had a shorter LOS (9 vs 17 days, $\mathrm{p}<0.001$ ). No statistical significance was found for complications either $(2.80 \%$ vs $2.30 \%$, yes, $\mathrm{p}=0.559$ ).

\section{Patient expenditures after matching}

The medical costs for almost all payment items of patients, with an exception of materials fees $(\$ 12015$ vs $\$ 11236$, $\mathrm{p}=0.334$ ), were a significant difference in two subgroups of TKA as shown in table 5. The total average medical expenses of simultaneous TKA were $\$ 15385$ and staged
TKA was $\$ 16729$, with a different value of $\$ 1344$. For other payment items of medical costs, the highest cost was materials fees ( $\$ 11236$ vs $\$ 12015$ ) and the lowest cost was nursing care fees ( $\$ 60$ vs $\$ 90$ ) (table 5 ).

Most of the medical costs are significantly higher in staged groups than simultaneous groups for bilateral THA, except for fees of general therapy ( $\$ 109$ vs $\$ 101$, $\mathrm{p}=0.671$ ) and materials fees ( $\$ 11697$ vs $\$ 11652, \mathrm{p}=0.888)$. The total average medical cost of patients who underwent a simultaneous bilateral THA was significantly lower than in those who received a staged bilateral THA ( $\$ 14503$ vs $\$ 16142$, $p=0.016$ ), with a different value of $\$ 1639$. The highest and the lowest costs were also materials fees and

Table 3 Baseline characteristics of patients (after matching)

\begin{tabular}{|c|c|c|c|c|c|c|c|c|c|}
\hline \multirow{2}{*}{$\begin{array}{l}\text { Groups } \\
\text { Variables }\end{array}$} & \multicolumn{3}{|l|}{ TKA } & \multicolumn{3}{|l|}{ THA } & \multicolumn{3}{|l|}{ TJA } \\
\hline & $\begin{array}{l}\text { Simultaneous } \\
(\mathrm{n}=309)\end{array}$ & Staged $(n=309)$ & $P$ value & $\begin{array}{l}\text { Simultaneous } \\
(n=100)\end{array}$ & $\begin{array}{l}\text { Staged } \\
(n=100)\end{array}$ & $P$ value & $\begin{array}{l}\text { Simultaneous } \\
(n=529)\end{array}$ & $\begin{array}{l}\text { Staged } \\
(n=529)\end{array}$ & $P$ value \\
\hline $\begin{array}{l}\text { Age, median (IQR) } \\
\text { years }^{\star}\end{array}$ & 65 (62-65) & $66(62-70)$ & 0.197 & $54(50-62)$ & $57(48-62)$ & 0.157 & 64 (59-69) & $64(58-70)$ & 0.85 \\
\hline Gender (female) $\dagger$ & 255 (82.50\%) & 256 (82.80\%) & 0.915 & $30(30.00 \%)$ & 29 (29.00\%) & 0.877 & 361 (68.20\%) & $356(67.30 \%)$ & 0.742 \\
\hline $\begin{array}{l}\text { BMI, median (IQR) } \\
\mathrm{kg} / \mathrm{m}^{2 \star}\end{array}$ & $\begin{array}{l}27.47(24.82- \\
30.39)\end{array}$ & $\begin{array}{l}27.48(25.34- \\
29.48)\end{array}$ & 1 & $\begin{array}{l}25.32(22.49- \\
26.99)\end{array}$ & $\begin{array}{l}24.60(22.60- \\
27.65)\end{array}$ & 0.48 & $\begin{array}{l}26.40(23.88- \\
29.14)\end{array}$ & $\begin{array}{l}27.04(24.22- \\
29.36)\end{array}$ & 0.05 \\
\hline Diabetes (yes)† & $56(18.10 \%)$ & 46 (14.90\%) & 0.279 & $2(2.00 \%)$ & $2(2.00 \%)$ & 1 & 59 (11.20\%) & 70 (13.20\%) & 0.301 \\
\hline $\begin{array}{l}\text { Coronary heart } \\
\text { disease (yes) } †\end{array}$ & 45 (14.60\%) & 53 (17.20\%) & 0.378 & $2(2.00 \%)$ & $2(2.00 \%)$ & 1 & 54 (10.20\%) & 56 (10.59\%) & 0.84 \\
\hline $\begin{array}{l}\text { Disease of } \\
\text { respiratory system } \\
\text { (yes) } \dagger\end{array}$ & 35 (4.44\%) & $18(5.80 \%)$ & 0.62 & $3(3.00 \%)$ & $1(1.00 \%)$ & 0.312 & $29(5.50 \%)$ & 26 (4.90\%) & 0.678 \\
\hline
\end{tabular}

${ }^{*}$ Continuous data were presented as median (IQR) and compared by Mann-Whitney $U$ test.

†Categorical variables were expressed by counts and percentages and compared by the $\mathrm{X}^{2}$ test or the Fisher's exact test, as appropriate.

$\mathrm{BMI}$, body mass index; THA, total hip arthroplasty; TJA, total joint arthroplasty; TKA, total knee arthroplasty. 
Table 4 Clinical characteristics of patients (after matching)

\begin{tabular}{|c|c|c|c|c|c|c|c|c|c|}
\hline Groups & TKA & & & THA & & & TJA & & \\
\hline Variables & $\begin{array}{l}\text { Simultaneous } \\
(n=309)\end{array}$ & $\begin{array}{l}\text { Staged } \\
(n=309)\end{array}$ & $P$ value & $\begin{array}{l}\text { Simultaneous } \\
(n=100)\end{array}$ & $\begin{array}{l}\text { Staged } \\
(n=100)\end{array}$ & $P$ value & $\begin{array}{l}\text { Simultaneous } \\
(n=529)\end{array}$ & $\begin{array}{l}\text { Staged } \\
(n=529)\end{array}$ & $P$ value \\
\hline $\begin{array}{l}\text { LOS, median (IQR) } \\
\text { days }^{*}\end{array}$ & $9(8-11)$ & 17 (15-20) & $<0.000$ & $9(8-11)$ & $15(14-18)$ & $<0.000$ & $9(8-11)$ & $17(15-20)$ & $<0.000$ \\
\hline
\end{tabular}

*Continuous data were presented as median (IQR) and compared by Mann-Whitney U test.

†Categorical variables were expressed by counts and percentages and compared by the $\mathrm{X}^{2}$ test or the Fisher's exact test, as appropriate. LOS, length of stay; THA, total hip arthroplasty; TJA, total joint arthroplasty; TKA, total knee arthroplasty.

nursing care fees $(\$ 60$ vs $\$ 92, \mathrm{p}<0.000)$, respectively (table 5).

In general, the same results were presented for TJA. Costs of bed fees, fees of general therapy, nursing care fees, check-up and laboratory test fees, surgical fees and drug fees were significantly lower compared with their counterparts (simultaneous TJA vs staged TJA, all, $\mathrm{p}<0.001)$. The comparison among materials fees has a different result with no statistical significance ( $\$ 12066$ vs $\$ 11368, \mathrm{p}=0.325)$. Moreover, the total medical cost was significantly higher in patients who received a staged TJA than in those who underwent a simultaneous TJA (\$16830 vs \$15389). Just like TKA and THA, the same trend for the highest and the lowest costs, they were materials fees and nursing care fees ( $\$ 60$ vs $\$ 89$ ), respectively (table 5).

\section{DISCUSSION}

Despite bilateral knee and hip arthroplasty being frequently performed, most studies paid attention to clinical outcomes, and only a few studies have been published recently on this topic. However, previous studies have not compared costs about THA, to say nothing of comparing costs when pooled both THA and TKA patients. ${ }^{27}$ In this study, we compared the cost of simultaneous and staged procedures among TKA, THA and TJA groups, found a significant difference between the two procedures in three groups. Viewing the general conclusions as a whole, the results showed that most of the hospital costs were higher in staged TKA, THA and combination of staged groups.

Our results are consistent with previous studies, which have estimated the economy of simultaneous TKA or

\begin{tabular}{|c|c|c|c|c|c|c|c|c|c|}
\hline \multirow{2}{*}{$\begin{array}{l}\text { Groups } \\
\text { Variables }\end{array}$} & \multicolumn{3}{|l|}{ TKA } & \multicolumn{3}{|l|}{ THA } & \multicolumn{3}{|l|}{ TJA } \\
\hline & $\begin{array}{l}\text { Simultaneous } \\
(\mathrm{n}=309)\end{array}$ & Staged $(n=309)$ & $P$ value & $\begin{array}{l}\text { Simultaneous } \\
(n=100)\end{array}$ & Staged $(n=100)$ & $P$ value & $\begin{array}{l}\text { Simultaneous } \\
(n=529)\end{array}$ & Staged $(n=529)$ & $P$ value \\
\hline $\begin{array}{l}\text { Total } \\
\text { medical } \\
\text { expenses }\end{array}$ & $\begin{array}{l}15385(14415- \\
16450)\end{array}$ & $\begin{array}{l}16729 \text { (14583- } \\
18041)\end{array}$ & $<0.000$ & $\begin{array}{l}14503(12548- \\
16771)\end{array}$ & $\begin{array}{l}16142(14557- \\
19246)\end{array}$ & 0.016 & $\begin{array}{l}15389 \text { (12378- } \\
16533)\end{array}$ & $\begin{array}{l}16830(14912- \\
18303)\end{array}$ & $<0.000$ \\
\hline $\begin{array}{l}\text { Nursing } \\
\text { care fees }\end{array}$ & $60(36-74)$ & $90(61-111)$ & $<0.000$ & $60(37-73)$ & $92(65-115)$ & $<0.000$ & $60(35-73)$ & $89(60-113)$ & $<0.000$ \\
\hline $\begin{array}{l}\text { Check- } \\
\text { up and } \\
\text { laboratory } \\
\text { test fees }\end{array}$ & $486(440-563)$ & $1086(907-1265)$ & $<0.000$ & $475(428-544)$ & $925(817-1120)$ & $<0.000$ & $487(437-549)$ & $\begin{array}{l}1052 \\
882-1258)\end{array}$ & $<0.000$ \\
\hline Drug fees & 1355 (950-1879) & 2132 (1579-2499) & $<0.000$ & $1152(868-1730)$ & $2056(1405-2650)$ & $<0.000$ & $1302(931-1785)$ & $2197(1405-2595)$ & $<0.000$ \\
\hline $\begin{array}{l}\text { Materials } \\
\text { fees }\end{array}$ & $\begin{array}{l}11236(9500- \\
13398)\end{array}$ & $\begin{array}{l}12015 \text { (9702- } \\
12703)\end{array}$ & 0.334 & $\begin{array}{l}11652 \text { (9503- } \\
13920)\end{array}$ & $\begin{array}{l}11697 \text { (10307- } \\
14022)\end{array}$ & 0.888 & $\begin{array}{l}11368(9429- \\
13424)\end{array}$ & $\begin{array}{l}12066 \text { (10299- } \\
12953)\end{array}$ & 0.325 \\
\hline
\end{tabular}

All values are in US dollars (US\$).

All medical expenditures were presented as median (IQR) and compared by the Mann-Whitney $U$ test.

THA, total hip arthroplasty; TJA, total joint arthroplasty; TKA, total knee arthroplasty. 
THA, compared with staged TKA or THA. ${ }^{215}$ 20-22 A study from Taiwan demonstrated that all categories of medical costs, except for therapeutic procedure fees, were lower in the simultaneous TKA group. ${ }^{2}$ However, a recent single-centre study concluded that there was no significant difference in total hospital costs between two groups of TKA, and it might be explained that the majority of their patients who received simultaneous TKA underwent inpatient rehabilitation (IPR) unit admission, and IPR costs were added for all patients discharged to IPR. ${ }^{7}$

At the same time, many studies including our study have found a shorter LOS in simultaneous TKA and THA. The median LOS for the simultaneous group is at an average level in our hospital. Compared with simultaneous surgery, staged surgery will increase the number of anaesthetics and hospital admissions, which usually means a longer LOS which has been regarded as a pivotal indicator of hospital efficiency and quality of healthcare ${ }^{23}$ In our hospital, due to the large number of patients visiting each day, the period of reappointment hospitalisation after discharge is longer; and the average age of our patients is 66 years old, which is also one of the reasons for the long hospital bed days. Prolonged LOS will not only hurt health outcomes and cause iatrogenic illness easily, but also high hospital occupancy resulted in a resultant loss of efficiency and access, all of which would bring a marked increase in health expenses. ${ }^{24} 25$ This might explain the relationship between exceeding LOS with high cost, for long LOS unusually followed high costs. ${ }^{25-27}$

This study found no significant difference in in-hospital complications, whether it was TKA, THA or TJA groups. Previous studies about complications differ from each other. Kamath et al did not find significant differences for complications between the simultaneous THA group and the staged THA group either. When it turns to TKA, several studies reported a lower rate of complications in the simultaneous TKA group. ${ }^{13} 15162227$ Whereas some studies have reported a higher rate of specific complications, such as venous thromboembolism ${ }^{7}$ and myocardial infarction ${ }^{28}$ for the patients older than 65 years in the simultaneous TKA group. However, Sheth et $a l^{29}$ considered that the differences in the baseline characteristics of the patients, surgeon's preference, and hospital characteristics may hamper the prior comparisons of complications between simultaneous TKA and staged TKA. They compared these two subgroups by adjusting for these differences, finding no significant difference in complication rates between the two subgroups. Our research also uses propensity score matching to control the basic condition of patients. A meta-analysis ${ }^{30}$ also proved no significant differences in complication rates. Moreover, studies that reported a higher rate of complication usually concentrated on certain complications, while our studies emphasised the total number of in-hospital complications.

However, we also found a higher incidence of blood transfusion in the simultaneous groups compared with staged groups in all three groups. Sobh et $^{7} \mathrm{l}^{\mathrm{i}}$ in a single institution of 562 patients, reported a significantly increased rate of blood transfusion with simultaneous TKA, and the same result was found in using a large Canadian data set. ${ }^{12}$ A series of bilateral total knee or hip arthroplasty, performed at a staged interval, would have more time for haematopoiesis to replenish blood loss because of the first surgery. ${ }^{31}$ Most of the staged patients in our study waited more than 6 months between procedures. Kamath et al found no blood transfusion in either group, but a higher blood loss in the staged group for THA. Because of the limitation of data, we could not analyse the volume of blood transfused. Further study needs to clarify the relationship between blood loss volume and different ways of procedures. As different blood transfusion practices and standards of reporting in different hospitals and surgeons would influence the final result, the interpretation of these results should be cautious.

These results may have important implications for the insurance department in the current healthcare environment. The cost of different surgeries for TKA and THA was different enough to warrant a separate classification for different procedures. Our results showed that staged bilateral TKA and THA have a greater financial cost than simultaneous bilateral TKA and THA, combined with the different clinical results of previous studies, suggesting that the two procedures should be classified separately for more accurate reimbursement. However, simultaneous bilateral TKA and THA and staged bilateral TKA and THA (calculated two surgical operations and reimbursed twice) are currently classified under the same diagnosisrelated groups, which means that they are reimbursed at the same level. Since medical insurance is the primary payer for patients in China, ${ }^{32}$ there needs reclassification of medical insurance items about these two procedures.

Limitations should be listed. First, we investigated data from a single institution that performed a relatively high rate of TKA and THA, and the universality of this study may be limited. However, this provided consistency in factors that might potentially affect clinical and financial outcomes, such as hospital characteristics, patient selection, surgeon skill and clinical equipoise. In China, THA and TKA have clinical pathways. Therefore, all our diagnosis and treatment processes are carried out strictly under the guidance of clinical pathways. Of course, we must also acknowledge the complexity of medical treatment. However, according to the guidance of standardised clinical pathways, a doctor's subjective preference has less influence. Second, we did not analyse too many clinical outcomes because of the limitation of data, but our study aims to compare the medical expenditures and a fair number of previous studies have compared direct clinical outcomes. Third, due to the lack of follow-up data of patients after discharge from the hospital, we do not know the subsequent costs of patients and fail to capture readmission data. This is also the limitation of retrospective research. A study by Hart $e t a l^{33}$ found that two-thirds of all patients with simultaneous bilateral surgery went to 
rehab facilities, versus a quarter of patients with unilateralonly surgery. This suggests that the bilateral cases might be more difficult for their rehabilitation and have a more significant burden. Therefore, our research results need to be treated with caution. For future research, the follow-up survey of patients after discharge from the hospital is a relatively blank and important study.

\section{CONCLUSION}

The three groups of patients between the two subgroups had similar results, and no significant differences were found in in-hospital complications. All kinds of medical expenses, except for materials fees and fees of general therapy, are lower for the simultaneous bilateral procedure, compared with a staged bilateral procedure whether it is TKA or THA or pooled groups. We also noted a significant difference in LOS, and the trends were the same as the costs. But simultaneous groups noted an increase in the risk of blood transfusion. Since our expenses are limited to costs incurred during hospitalisation, the conclusion needs to be treated with caution.

Acknowledgements The authors would like to thank all the surgeons for giving permission to use their data.

Contributors All authors have contributed to this study. J-FH and $\mathrm{CH}$ conceived and designed this study. J-FH wrote the draft of this paper. $\mathrm{CH}$ and L-QT assisted in the collation and arrangement of the data presented. Y-ZL and L-QT did writing assistance and proofreading the article. $\mathrm{JL}$ and $\mathrm{CZ}$ guided in statistical analysis of this study and helped in the interpretation of the data. Y-ZL contributed to study coordination and was responsible for the English spelling and grammar. YZ was in charge of revision and guidance during the whole writing process of this thesis. All authors have participated in discussion, read and approved the final manuscript.

Funding The authors have not declared a specific grant for this research from any funding agency in the public, commercial or not-for-profit sectors.

Competing interests None declared.

Patient and public involvement Patients and/or the public were not involved in the design, or conduct, or reporting, or dissemination plans of this research.

Patient consent for publication Not required.

Ethics approval This study was reviewed and approved by the Ethics Committee of the Affiliated Hospital of Qingdao University.

Provenance and peer review Not commissioned; externally peer reviewed.

Data availability statement Data are available upon reasonable request. The data sets supporting the conclusions of this article are included within the article/tables. The raw data can be requested from the corresponding author.

Open access This is an open access article distributed in accordance with the Creative Commons Attribution Non Commercial (CC BY-NC 4.0) license, which permits others to distribute, remix, adapt, build upon this work non-commercially, and license their derivative works on different terms, provided the original work is properly cited, appropriate credit is given, any changes made indicated, and the use is non-commercial. See: http://creativecommons.org/licenses/by-nc/4.0/.

ORCID iD

Yun Zhang http://orcid.org/0000-0002-1358-6667

\section{REFERENCES}

1 Kamath AF, Monteiro EL, Spranger A, et al. Simultaneous versus staged bilateral direct anterior total hip arthroplasty: are early patientcentered outcomes equivalent? Acta Orthop Belg 2016;82:497-508.

2 Lin AC-C, Chao E, Yang C-M, et al. Costs of staged versus simultaneous bilateral total knee arthroplasty: a population-based study of the Taiwanese National health insurance database. $J$ Orthop Surg Res 2014;9:59.

3 Ethgen $O$, Bruyère $O$, Richy $F$, et al. Health-related quality of life in total hip and total knee arthroplasty. A qualitative and systematic review of the literature. J Bone Joint Surg Am 2004;86:963-74.

4 Sloan M, Premkumar A, Sheth NP. Projected volume of primary total joint arthroplasty in the U.S., 2014 to 2030. J Bone Joint Surg Am 2018;100:1455-60.

5 Kurtz SM, Ong KL, Lau E, et al. Impact of the economic downturn on total joint replacement demand in the United States: updated projections to 2021. J Bone Joint Surg Am 2014;96:624-30.

6 Pei F-xing. The current status and future perspective of hip and knee arthroplasty in China. Chinese J Bone Joint 2012;1:V4-8.

7 Sobh AH, Siljander MP, Mells AJ, et al. Cost analysis, complications, and discharge disposition associated with simultaneous vs staged bilateral total knee arthroplasty. $J$ Arthroplasty 2018;33:320-3.

8 Hustedt JW, Goltzer O, Bohl DD, et al. Calculating the cost and risk of comorbidities in total joint arthroplasty in the United States. $J$ Arthroplasty 2017;32:355-61.

9 Elmallah RK, Chughtai M, Khlopas A, et al. Determining costeffectiveness of total hip and knee arthroplasty using the short Form6D utility measure. J Arthroplasty 2017;32:351-4.

10 Peel TN, Cheng AC, Liew D, et al. Direct hospital cost determinants following hip and knee arthroplasty. Arthritis Care Res 2015;67:782-90.

$11 \mathrm{Ma} \mathrm{C}$, Jiang Y, Li Y, et al. Medical expenditure for middle-aged and elderly in Beijing. BMC Health Serv Res 2019;19:360.

12 Bohm ER, Molodianovitsh K, Dragan A, et al. Outcomes of unilateral and bilateral total knee arthroplasty in 238,373 patients. Acta Orthop 2016;87:24-30.

13 Seol J-H, Seon J-K, Song E-K. Comparison of postoperative complications and clinical outcomes between simultaneous and staged bilateral total knee arthroplasty. J Orthop Sci 2016;21:766-9.

14 Courtney PM, Melnic CM, Alosh H, et al. Is bilateral total knee arthroplasty staged at a one-week interval safe? A matched case control study. J Arthroplasty 2014;29:1946-9.

15 Odum SM, Troyer JL, Kelly MP, et al. A cost-utility analysis comparing the cost-effectiveness of simultaneous and staged bilateral total knee arthroplasty. J Bone Joint Surg Am 2013;95:1441-9.

16 Stanley D, Stockley I, Getty CJ. Simultaneous or staged bilateral total knee replacements in rheumatoid arthritis. A prospective study. $J$ Bone Joint Surg Br 1990;72:772-4.

17 National bureau of statistics of china. National data reports from China, 2019. Available: http://data.stats.gov.cn/search.htm?s=CPI [Accessed 20 Nov 2019].

18 National bureau of statistics of china. National data reports from China, 2019. Available: http://data.stats.gov.cn/easyquery.htm?cn= C01\&zb=A060J\&sj=2017 [Accessed 20 Nov 2019].

19 Austin PC. An introduction to propensity score methods for reducing the effects of confounding in observational studies. Multivariate Behav Res 2011;46:399-424.

20 Reuben JD, Meyers SJ, Cox DD, et al. Cost comparison between bilateral simultaneous, staged, and unilateral total joint arthroplasty. J Arthroplasty 1998;13:172-9.

21 Brotherton SL, Roberson JR, de Andrade JR, et al. Staged versus simultaneous bilateral total knee replacement. J Arthroplasty 1986;1:221-8.

22 Ritter MA, Meding JB. Bilateral simultaneous total knee arthroplasty. $J$ Arthroplasty 1987;2:185-9.

23 Barba R, Marco J, Canora J, et al. Prolonged length of stay in hospitalized internal medicine patients. Eur J Intern Med 2015;26:772-5.

24 Doctoroff L, Hsu DJ, Mukamal KJ. Trends in prolonged hospitalizations in the United States from 2001 to 2012: a longitudinal cohort study. Am J Med 2017;130:483.e1

25 Shinjo D, Tachimori H, Sakurai K, et al. Factors affecting prolonged length of stay in psychiatric patients in Japan: a retrospective observational study. Psychiatry Clin Neurosci 2017;71:542-53.

26 Abdullah HR, Sim YE, Hao Y, et al. Association between preoperative anaemia with length of hospital stay among patients undergoing primary total knee arthroplasty in Singapore: a single-centre retrospective study. BMJ Open 2017;7:e016403.

27 Yoon H-S, Han C-D, Yang I-H. Comparison of simultaneous bilateral and staged bilateral total knee arthroplasty in terms of perioperative complications. J Arthroplasty 2010;25:179-85.

28 Bolognesi MP, Watters TS, Attarian DE, et al. Simultaneous vs staged bilateral total knee arthroplasty among Medicare beneficiaries, 20002009. J Arthroplasty 2013;28:87-91. 
29 Sheth DS, Cafri G, Paxton EW, et al. Bilateral simultaneous vs staged total knee arthroplasty: a comparison of complications and mortality. J Arthroplasty 2016;31:212-6.

30 Hussain N, Chien T, Hussain F, et al. Simultaneous versus staged bilateral total knee arthroplasty: a meta-analysis evaluating mortality, peri-operative complications and infection rates. Hss J 2013;9:50-9.

$31 \mathrm{Fu} \mathrm{D}$, Li G, Chen K, et al. Comparison of clinical outcome between simultaneous-bilateral and staged-bilateral total knee arthroplasty: a systematic review of retrospective studies. J Arthroplasty 2013;28:1141-7.

32 Dou G, Wang Q, Ying X. Reducing the medical economic burden of health insurance in China: achievements and challenges. Biosci Trends 2018;12:215-9.

33 Hart A, Antoniou J, Brin YS. Simultaneous bilateral versus unilateral total knee arthroplasty: a comparison of 30-day readmission rates and major complications. J Arthroplasty 2016;31:1616. 